\title{
Short-Range Guidance of Olfactory Bulb Axons Is Independent of Repulsive Factor Slit
}

\author{
Tatsumi Hirata, ${ }^{1,2,3}$ Hajime Fujisawa,,$^{3,4}$ Jane Y. Wu, ${ }^{5}$ and Yi Rao ${ }^{6}$ \\ ${ }^{1}$ Division of Brain Function, National Institute of Genetics, Mishima 411-8540, Japan, 2Precursory Research for \\ Embryonic Science and Technology and ${ }^{3}$ Core Research for Evolution Science and Technology, Japan Science and \\ Technology Corporation, Kawaguchi 332-0012, Japan, ${ }^{4}$ Division of Biological Science, Nagoya University Graduate \\ School of Science, Chikusa-ku, Nagoya 464-8602, Japan, 5Departments of Pediatrics and Molecular Biology and \\ Pharmacology, and 'Anatomy and Neurobiology, Washington University School of Medicine, St. Louis, Missouri 63110
}

\begin{abstract}
During development, mitral cells, the major output neurons of the olfactory bulb, project their axons caudolaterally into the telencephalon and form the lateral olfactory tract (LOT). Two types of guidance cues have been suggested for this projection. First, a long-range factor Slit, which is secreted from the septum, repels mitral cell axons into a caudolateral direction. Second, the pathway of mitral cell axons contains a subset of neurons designated as lot cells, which guide the axons through short-range interactions. It is not clear how these two guidance cues relate to each other and how they share the physiological roles. Here we examined the behavior of mitral cell axons in organotypic culture on ectopic application of Slit and inhibition
\end{abstract}

of endogenous Slit signaling. The results suggested that the short-range guidance cue in the LOT pathway functions independently from Slit. Furthermore, our results showed that removal of the septum and inhibition of Slit signaling did not affect the projection of mitral cell axons. Although the septum and exogenous Slit can repel olfactory bulb axons, our results cast doubts on the physiological relevance of the septum and endogenous Slit in guiding the projection of mitral cell axons.

Key words: development; growth; mitral cells; lateral olfactory tract; Slit; guidance cue
In the developing nervous system, axons often navigate through a long distance toward their targets. At some points along the navigation course, axons encounter guidance cues, which attract or repel axons into specific pathways. Certain cues are secreted from a detached source and act on axons over long range, whereas others are immobilized on cellular membranes or the extracellular matrix and act on axons at short range (Goodman and Shatz, 1993; Tessier-Lavigne and Goodman, 1996). The complete projection of axons sometimes require multiple guidance cues that differ in the source, range, and action.

Several studies have examined the mechanisms of axonal guidance using simple model systems, such as the central olfactory projection (Schwob and Price, 1984; Brunjes and Frazier, 1986). The major output neurons of the olfactory bulb, mitral cells, project long axons caudolaterally into the telencephalon and form the lateral olfactory tract (LOT) (Fig. $1 A, B$ ). Although the projection is simple, two types of guidance cues are proposed in this system. First, before the first mitral cell axons grow out of the olfactory bulb, the future pathway of these axons is already

\footnotetext{
Received Oct. 11, 2000; revised Jan. 3, 2001; accepted Jan. 4, 2001.

T.H. acknowledges the support by grants from the Ministry of Education and Science and Culture, Precursory Research for Embryonic Science and Technology, and Core Research for Evolution Science and Technology of Japan Science and Technology Corporation. Y. R. and J.Y.W. acknowledge support from the National Institutes of Health and the John Merck Fund. We thank Dr. Kensuke Nakahira of the National Institute for Physiological Science and Dr. Takayoshi Inoue of the National Institute of Neuroscience for helpful advice, and Dr. Yasushi Hiromi of the National Institute of Genetics for critical reading of this manuscript.

Correspondence should be addressed to Dr. Tatsumi Hirata, Division of Brain Function, National Institute of Genetics, Yata 1111, Mishima 411-8540, Japan. E-mail: tathirat@lab.nig.ac.jp.

Copyright (C) 2001 Society for Neuroscience $\quad 0270-6474 / 01 / 212373-07 \$ 15.00 / 0$
}

marked with a specific array of early-generated neurons called lot cells, which are recognized by monoclonal antibody (mAb) lot1 (Sato et al., 1998). Growing mitral cell axons strictly follow this cellular array, and pharmacological ablation of lot cells stalls the growth of mitral cell axons (Sato et al., 1998). Coculture experiments have shown that mitral cell axons must contact lot cells to grow (Sugisaki et al., 1996; Sato et al., 1998), suggesting a shortrange guidance cue from lot cells (LOT cue). The molecular nature of the LOT cue is yet unknown. Second, mitral cell axons are also guided by a long-range cue. When the olfactory bulb is cocultured in collagen gel with the septum that positions caudomedially next to the olfactory bulb (Fig. $1 A, B$ ), mitral cell axons are repelled by a factor released from the septum (Pini, 1993). This repulsive activity was recently identified as Slit, a large secreted protein (Li et al., 1999; Tuyen et al., 1999). These studies together suggest that the septum secretes Slit, which directs mitral cell axons into a lateral direction to form the LOT. When Slit is ectopically applied to the whole-telencephalon preparation, it repels mitral cell axons growing along the natural pathway, seemingly by overriding the LOT cue (Li et al., 1999).

These two guidance cues for mitral cell axons may not be independent but rather interdependent (Fig. 1C). For example, lot cells might inactivate Slit and allow mitral cell axons to grow along these cells (Slit-Inactivation model). Alternatively, lot cells might enhance the tolerance of mitral cell axons to Slit, so that the axons could elongate on lot cells in the presence of Slit (Slit-Tolerance model). An analogous scenario actually operates in Drosophila; midline glial cells downregulate the receptor for Slit, Roundabout (Robo) from commissural axons, thereby allowing the axons to grow on these cells (Tear et al., 1996; Kidd et al., 1998, 1999). In addition to these models, the overriding action of 
Figure 1. Mitral cell projection and possible guidance models. $A, B$, Schematic drawings of the rostral view $(A)$ and lateral view $(B)$ of E14.5 mouse telencephalons. The dorsal aspect is to the top in both views. The medial and rostral aspects are to the left in $A$ and $B$, respectively. Mitral cells $(M t)$ in the olfactory bulb $(O B)$ project axons into a lateral direction, avoiding the septum, and form the LOT on the lateral surface of the telencephalon. In the lateral view $(B)$, the septum sits behind the telencephalon wall. $C$, Four possible models of the mitral cell guidance. Green circles symbolize Slit proteins, and red arrowheads symbolize LOT cues. In the Slit-Inactivation model, the LOT cue downregulates repulsive activity of Slit by processes, such as degradation, trapping, and neutralization, and allows the axons to grow along lot cells. In the Slit-Tolerance model, the LOT cue acts on mitral cell axons and makes them refractory to Slit, so that the axons can elongate in the presence of Slit proteins. In the Slit-Determinant model, Slit controls the distribution of the LOT cue. In the Parallel Model, Slit and LOT cue independently act on mitral cell axons. Green arrows and red arrows show directions of actions of Slit and the LOT cue, respectively.
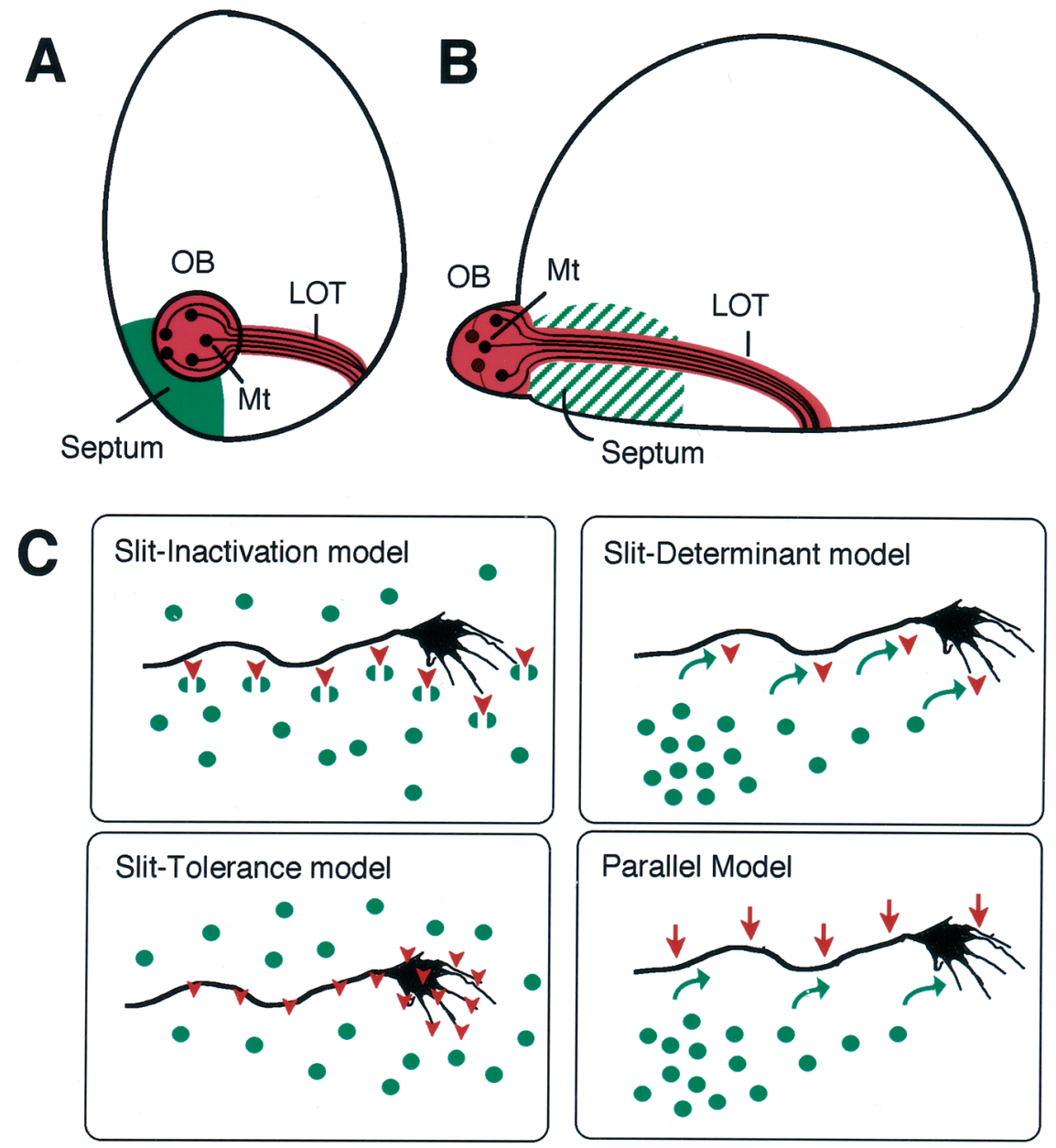

Parallel Model

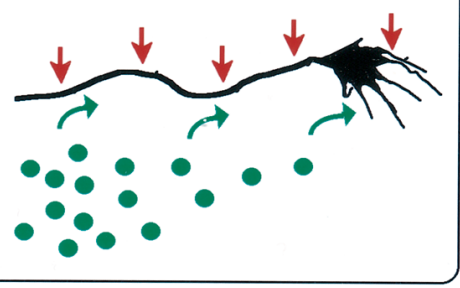

Slit on the LOT cue suggests another class of interaction; Slit also controls the distribution or establishment of the LOT cue (SitDeterminant model). Slit repels various types of neuronal migration (Hu, 1999; Wu et al., 1999; Z hu et al., 1999), whereas lot cells are one of those neurons that migrate for a long distance before aligning in the presumptive LOT position (Tomioka et al., 2000). It is possible that the migration or alignment of lot cells is regulated by Slit.

If one of these interactive models is correct, what can be expected? In all of the interactive models, Slit is assumed to be the basis to produce the guiding force of the LOT cue (Fig. 1C). Thus, in the absence of Slit signaling, the LOT cue would no longer exist. Ectopic application of Slit would also severely affect the LOT cue if these two cues functionally interact. In the Slit-determinant model, the ectopic gradient of Slit would distort the LOT cue. In the Slit-inactivation or Slit-tolerance model, Slit overload may again disrupt the LOT cue, in which mitral cell axons ignore the LOT position and just obey the Slit gradient. In contrast, if Slit and the LOT cue independently function in guiding mitral cell axons (Fig. 1C, Parallel Model), such perturbations of Slit signaling would only produce a minor effect on the LOT cue. The two cues would coexist, allowing mitral cell axons to follow both guiding cues at the same time.

The above models were tested in the present study. We transplanted Slit-expressing cells near the LOT position in a wholetelencephalon preparation and analyzed the effects of ectopic Slit on the LOT cue in organotypic culture. We also removed the septum, the major source of Slit, from the whole-telencephalon preparation and cultured the preparation in the presence of the extracellular domain of Robo (RoboN) to inhibit endogenous Slit signaling. Our results supported the parallel model that Slit and the LOT cue can independently act on mitral cell axons. Furthermore, the present study questioned whether Slit signaling is physiologically required for the guidance of mitral cell axons.

\section{MATERIALS AND METHODS}

Mice. Timed-pregnant ICR mice were purchased from SLC (Shizuoka, Japan). The day that a vaginal plug was found was considered as embryonic day 0.5 (E0.5). The dams were deeply anesthetized with ether, and the embryos were dissected out.

Whole-telencephalon organotypic culture. The method of organotypic culture has been described previously (Sugisaki et al., 1996; Hirata and Fujisawa, 1999). Briefly, telencephalon hemispheres together with the olfactory bulbs were excised from E12.5 mouse embryos and freed from the pia mater. The lateral part of hemisphere was isolated by trimming the medial side of the neocortex and protrusion of the medial ganglionic eminence. The major part of the septum was usually removed in preparations. For septum-free preparations, the entire septum was completely removed with utmost care. As a control, septum-retained preparations were used without any trimming of the septum. These preparations were placed on collagen-coated membrane filters (Transwell-col; Costar, Cambridge, MA) ventricular side down and cultured in a 1:1 mixture of DMEM (Nissui, Tokyo, Japan) and Ham F-12 medium (Nissui) supplemented with $10 \%$ fetal bovine serum (JRH Bioscience, Lenexa, KS) and $5 \%$ horse serum (Life Technologies, Rockville, MD) at $37^{\circ} \mathrm{C}$ for $2 \mathrm{~d}$.

Transplantation of human embryonic kidney cell aggregates. The pro- 
duction of human embryonic kidney (HEK) cells stably expressing fulllength Xenopus Slit and control HEK cells was described previously ( $\mathrm{Li}$ et al., 1999). Aggregates of cells were prepared by the hanging-drop method (Fan and Tessier-Lavigne, 1994) and trimmed into square pieces with $200-500 \mu \mathrm{m}$ sides by a fine tungsten needle. The aggregate was placed on the surface of a whole-telencephalon preparation that had been freshly set on a membrane filter and then carefully dragged close to the LOT position with a tungsten needle under a dissecting microscope. After culture of the preparation, the position of cell aggregates was determined under the microscope. Only preparations that had aggregates within $200 \mu \mathrm{m}$ distance from the LOT position were analyzed.

Inhibition of Slit signaling by RoboN. RoboN, the hemagglutinin-tagged extracellular domain of Robo, was expressed in HEK cells as described previously (Wu et al., 1999; Zhu et al., 1999). These cells were cultured in a serum-free culture medium (GIT medium; Wako, Osaka, Japan) until they formed a confluent monolayer. The conditioned medium was then collected and concentrated 10-fold with a centrifugal filter device (Centriprep; Millipore, Bedford, MA). The concentrated medium was dialyzed against the DMEM-Ham F-12 mixture and added to cultures in one-third dilution with the fresh culture medium.

Histochemistry. To visualize mitral cell axons, organotypic cultures of telencephalons were whole-mount immunostained with rabbit antineuropilin-1 antibody (Kawakami et al., 1996; Sugisaki et al., 1996). The binding of antibody was detected with FITC-labeled anti-rabbit Ig antibody (Amersham Pharmacia Biotech, Buckinghamshire, UK) in most of the preparations. When the binding was visualized with 3,3'diaminobenzidine (Wako), preparations were processed with Vectastain ABC elite kit (Vector Laboratories, Burlingame, CA). The whole-mount immunostaining with $\mathrm{mAb}$ lot 1 followed the previous procedures (Sato et al., 1998; Tomioka et al., 2000) and was visualized with Cy3-labeled anti-rat Ig antibody (Jackson ImmunoResearch, West Grove, PA). Whole-mount in situ hybridization was performed using digoxigenin (DIG)-labeled RNA probes that had been transcribed from mouse Slit1 and Slit2 cDNAs as described previously (Yuan et al., 1999). Hybridization signals were detected with AP-conjugated anti-DIG antibody (Roche, Mannheim, Germany) and nitroblue tetrazolium, 5-bromo-4chloro-3-indoyl phosphate (Roche). For anterograde labeling of mitral cell axons, a small crystal of 1,1-dioctadecyl-3,3,3'3'-tetra-methylindocarbacyanine perchlorate (DiI) (Molecular Probes, Eugene, OR) was inserted into the medial side of the olfactory bulb fixed with $4 \%$ paraformaldehyde. The preparation was kept in the fixative at $37^{\circ} \mathrm{C}$ for $6 \mathrm{~d}$ to fill the axons with the dye and was examined as described previously (Hirata and Fujisawa, 1999).

\section{RESULTS}

\section{Effect of the ectopic application of Slit on the LOT cue}

At E12.5, the first mitral cell axons are just about to grow out the olfactory bulb into the telencephalon (Sugisaki et al., 1996). By this stage, the future pathway of primary mitral cell axons has already been covered with lot cells; the cells are continuously distributed from the whole surface of the olfactory bulb to the presumptive LOT position, delineating a ladle-like shape (Sato et al., 1998). When the telencephalon is dissected out and cultured organotypically as a whole on a membrane filter, a number of mitral cell axons grow along the alignment of lot cells and form a LOT-like bundle (Sugisaki et al., 1996; Sato et al., 1998) (Fig. 2A,B).

We transplanted aggregates of HEK cells expressing Slit protein near the LOT position of the E12.5 telencephalon and organotypically cultured the telencephalon for $2 \mathrm{~d}$. The Slitexpressing cells did not affect the distribution of lot cells or the intensity of staining with mAb lot 1 ; lot cells maintained the ladle-shaped distribution, aligning their processes along the LOT position as these cells normally do in the telencephalon (Fig. $2 C, E, G)$. However, the Slit-expressing cells strikingly affected the projection of mitral cell axons. Probably according to the accessibility to Slit protein, mitral cell axons were repelled in various degrees (Fig. 3). In severe cases, mitral cell axons totally turned away by Slit-expressing cells and grew retrogradely into the bulb (Fig. 2D). In other cases, mitral cell axons turned away from the aggregates, elongated for a short distance, and then stopped (Fig. $2 F$ ). Interestingly, although these axons grew in an abnormal direction, they were still confined to the ladle-shaped region delineated by lot cells and never grew beyond that region (Fig. 2C,E). Once out of the olfactory bulb, mitral cell axons always followed the LOT pathway that had been marked with lot cells, although the axons often stalled halfway along the pathway (Fig. 2G,H). This region-restricted repulsion of axons was observed, whether Slit-expressing cells were transplanted on the ventral or dorsal side of the LOT position.

Two points can be noted from the results. First, ectopic application of Slit does not distort the LOT cue. Although the projection of mitral cell axons was severely disturbed by Slit, lot cells were still in the correct LOT position, arguing against the Slitdeterminant model in which Slit controls the distribution of the LOT cue. Second, mitral cell axons follow both guidance cues. Even when the axons were repelled by Slit and grew in a wrong direction, they still followed the ladle-shaped region delineated by lot cells. Conversely, even when the axons were guided in the growth-permitted ladle-shaped region, they were still sensitive to the ectopic gradient of Slit; the axons were repelled by the gradient inside the LOT position. Thus, the LOT cue does not seem to inactivate Slit or enhance the tolerance of mitral cell axons to Slit. Together, these results seem to support the parallel model that Slit and the LOT cue independently act on mitral cell axons.

\section{Effects of removal of the septum and inhibition of endogenous Slit signaling on mitral cell guidance}

Previous studies have identified three members of the mouse Slit family (Holmes et al., 1998; Itoh et al., 1998; Nakayama et al., 1998). Among these, Slit1 and Slit2 are expressed in the septum at E12.5 (Li et al., 1999; Tuyen et al., 1999) (Fig. 4A). To assess the role of endogenous Slit in mitral cell projection, we established two types of whole-telencephalon preparations; one maintained the entire septum, and the other was completely devoid of the septum. In the septum-free preparation, the expression of Slit1 or Slit2 was no longer detected by in situ hybridization (Fig. 4B).

The two types of preparations were organotypically cultured for $2 \mathrm{~d}$ and assayed for distribution of lot cells and projection of mitral cell axons. In both preparations, lot cells were distributed in a normal ladle-shaped pattern (data not shown). Moreover, the overall projection patterns of mitral cell axons were indistinguishable between the preparations; similar numbers of axons were projected from the olfactory bulb and formed prominent LOT bundles (Fig. 4C,D). Because the septum is adjacent to the medial side of the olfactory bulb, it is likely that mitral cell axons in the medial olfactory bulb are most accessible to endogenous Slit from the septum (Fig. 1A). Thus, axons from the medial side of the olfactory bulb were selectively labeled with fluorescent dye DiI and traced in detail. The medial mitral cell axons in septum-free preparations grew around the bulb, projected laterally, and joined the LOT bundle (Fig. $4 F$ ), resembling the pattern seen in preparations with the intact septum (Fig. $4 E$ ). Finally, the orderly projection of medial mitral cell axons was also observed when mitral cell axons were viewed from the medial side of the olfactory bulb; all axons projected laterally as if 


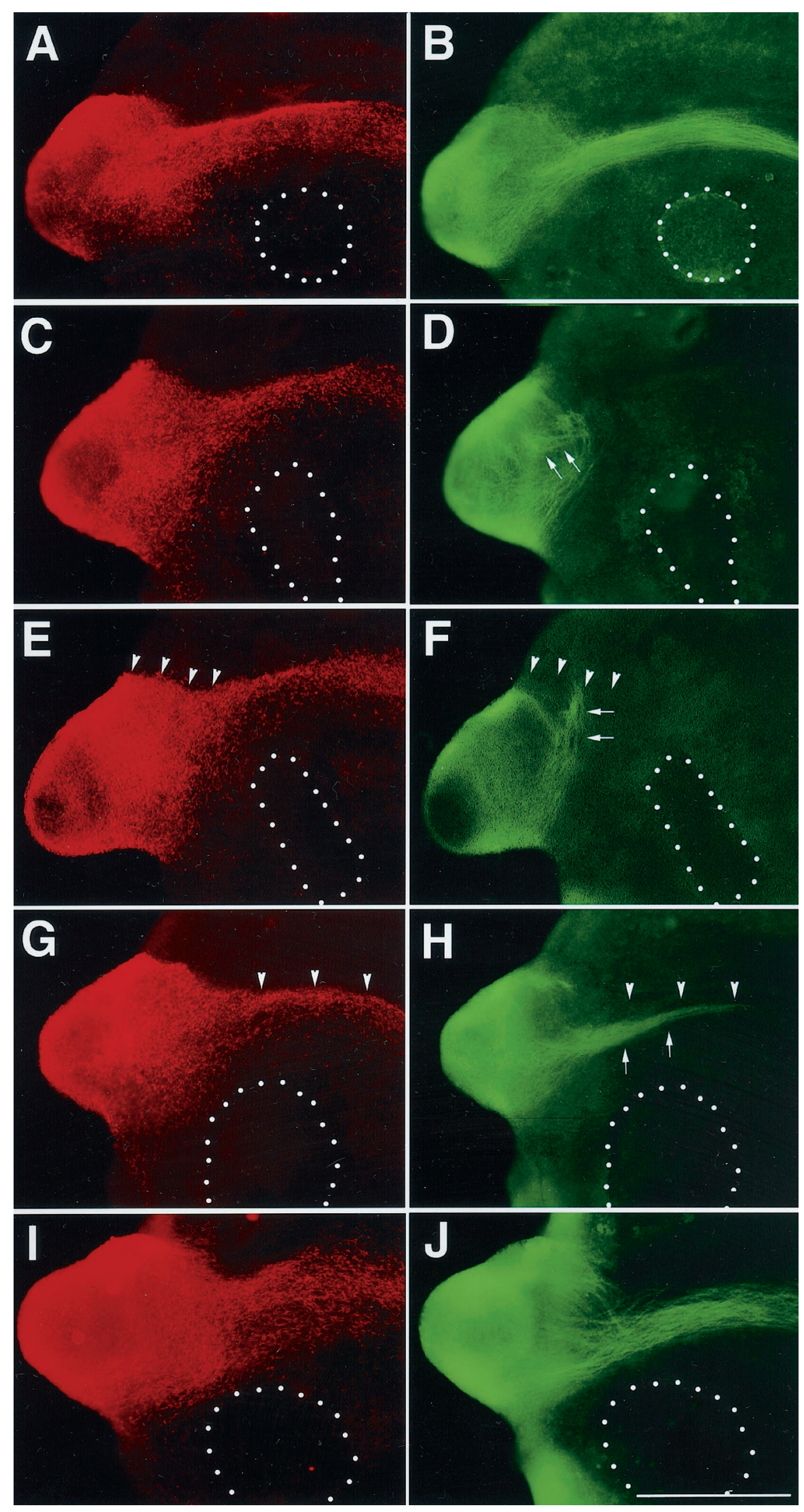

Figure 2. Effects of transplantation of Slitexpressing cells on the LOT cue. Aggregates of control HEK cells $(A, B)$ and Slit-expressing cells $(C-J)$ were placed on E12.5 telencephalons in the dotted lines, and the telencephalons were organotypically cultured for $2 \mathrm{~d}$ in the normal culture media $(A-H)$ or in the presence of RoboN $(I, J)$. A, $C, E, G, I$, Lot cells visualized with mAb lot1 (red). $B, D, F, H, J$, Mitral cell axons visualized with anti-neuropilin-1 antibody (green). The left and right panels in each row are identical fields. In $C$ and $D$, mitral cell axons are repelled by Slit-expressing cells and grow back into the olfactory bulb (arrows). In $E$ and $F$, mitral cell axons are repelled for a short distance (arrows) but are still confined to the area delineated by lot cells (arrowheads). In $G$ and $H$, once mitral cell axons grow out of the olfactory bulb, they always follow the LOT position at which lot cells align (arrowheads), although these axons often stall halfway along (arrows). In $I$ and $J$, the repulsive effect of Slit is inhibited by RoboN. Scale bar, $500 \mu \mathrm{m}$. 


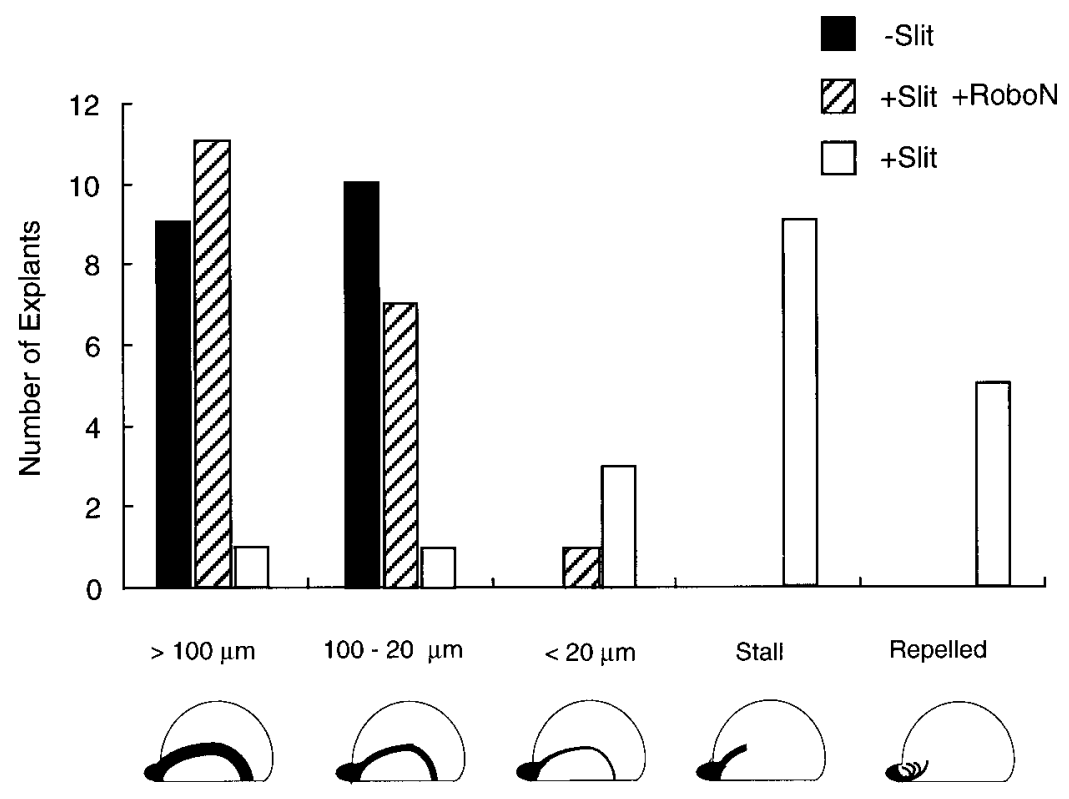

Figure 3. A histogram showing projection patterns of mitral cell axons in response to Slit-expressing cells and RoboN. E12.5 whole-telencephalon preparations were organotypically cultured for $2 \mathrm{~d}$ under various conditions and classified into five groups according to the projection patterns of mitral cell axons as follows: axons form the LOT bundle $>100-\mu \mathrm{m}-$ wide; axons form the LOT bundle 20- to 100- $\mu \mathrm{m}$-wide; some axons elongate throughout the entire LOT pathway but only form a bundle $<20-\mu \mathrm{m}$-wide; axons stall halfway along the LOT pathway as in Figure $2 H$; and axons that are repelled away toward the olfactory bulb as in Figure $2, D$ and $F$. Solid bars indicate the number of explants cultured without transplantation of Slit-expressing cells in normal culture media. Hatched bars indicate those transplanted with Slit-expressing cells and cultured in the presence of RoboN. Open bars indicate those transplanted with Slit-expressing cells and cultured in normal culture media. Slit-expressing cells strikingly repel and inhibit the growth of mitral cell axons, but the effects are blocked by RoboN.

repulsed from the medial side, although there was no tissue medial to the olfactory bulb (Fig. $4 G, H$ ).

It is possible that Slit protein had already been secreted before the removal of the septum and was somehow retained in preparations. It is also possible that regions other than the septum produce Slit at levels below detection by our in situ hybridization and influence the guidance. In fact, at slightly later stages, Slit1 mRNA has been detected in the olfactory bulb, ganglionic eminence, and neocortex (Tuyen et al., 1999; Yuan et al., 1999). To exclude the involvement of these putative Slit sources, we used RoboN, the extracellular domain of the Slit receptor. This partial protein binds Slit1 and Slit2 but cannot transduce the signal to intracellular compartments and thus acts as a competitive blocker of Slit signaling (Wu et al., 1999). RoboN completely blocks the repulsive activity of the septum on neuronal migrations in collagen gel cultures (Wu et al., 1999). When RoboN was added to the media of whole-telencephalon culture, it blocked the repulsion of mitral cell axons by Slit-expressing cells (Figs. 2I,J, 3). However, even when the same amount of RoboN was added to culture media containing septum-free telencephalons, mitral cell axons still projected normally and formed a prominent LOT bundle (Fig. 4I). Medial mitral cell axons grew around the bulb and projected in a lateral direction (Fig. 4J). The orderly projection was indistinguishable from the projection in control cultures or in vivo.

\section{DISCUSSION}

The present study supported the parallel model that Slit and the LOT cue can independently guide mitral cell axons. First, the ectopic application of Slit did not distort the LOT cue, suggesting that the Slit-determinant model is unlikely. Second, mitral cell axons appeared to be responsive to the ectopic gradient of Slit and the LOT cue at the same time, suggesting that the interactive models are less probable. Finally, the removal of the septum and succeeding blockage of endogenous Slit signaling did not alter the LOT cue. This result can only be explained by the parallel model.
An interesting observation in the present study is that mitral cell axons projected quite normally, even when the septum-free telencephalon was cultured in the presence of RoboN. This poses a question about the physiological role for endogenous Slit in the mitral cell projection. Slit released from the septum can repel mitral cell axons in collagen gel culture (Pini, 1993; Li et al., 1999), but the endogenous Slit may not be accessible to mitral cell axons in the living tissue (Brose et al., 1999; Liang et al., 1999). Nevertheless, before remarking the contribution of endogenous Slit, there are yet other possibilities that have to be considered. For example, although RoboN completely blocks the function of ectopic Slit in whole-telencephalon culture as well as endogenous Slit diffusing in collagen gels (Wu et al., 1999; Zhu et al., 1999), this does not necessarily mean that RoboN completely blocks the function of endogenous Slit in the living tissue under wholetelencephalon culture. The penetration of RoboN into the living tissue could be a problem. Failure of blocking endogenous Slit signalings would also weaken the cause for the former conclusion, i.e., interactions between Slit and the LOT cue are independent. For the present, however, we cannot measure the endogenous Slit activity and thus have to wait for future studies involving gene-targeting mice to completely abolish endogenous Slit.

The present study emphasizes the importance of the LOT cue in mitral cell guidance. The LOT cue, however, is not sufficient for the projection. We demonstrated previously that, although the LOT cue determines the pathway for mitral cell axons, it lacks the directional information to orient the axons caudolaterally; when the olfactory bulb is cocultured with the caudal end of the lot cell array, mitral cell axons grow backward toward a rostral direction, choosing the position of lot cells (Sugisaki et al., 1996). The directional information does not seem to be assigned to the Slit gradient, because medial mitral cell axons were still oriented caudolaterally while Slit signaling was inhibited. Moreover, the septum does not seem to be responsible for the directional information, although it has been considered as the source of long-range guidance cues for mitral cell axons. The directional information appears to reside in another loca- 
Figure 4. Effects of septum and inhibition of endogenous Slit signaling on mitral cell projection. $A, B$, Expression of mouse Slit2 mRNA in the E12.5 whole-telencephalon preparation containing the septum $(A)$ and free of the septum $(B)$. Medial views of the preparations. Rostral aspects are to the left. Signals are only detected in the septum (arrowhead) of $A$. Slit1 mRNA showed a similar expression pattern (data not shown). The septum-retained $(C, E, G)$ and septum-free $(D, F, H)$ telencephalons were organotypically cultured for $2 \mathrm{~d}$, and projection patterns of mitral cell axons were analyzed by various methods. $C, D$, Lateral views of telencephalons immunostained with anti-neuropilin-1 antibody. Mitral cell axons form the LOT bundles (arrows) in both telencephalons. $E, F$, DiI was injected on the medial side of the olfactory bulb and filled medial mitral cell axons. Lateral views of the rostral parts of telencephalons. DiI-labeled axons (arrows) turn around in the olfactory bulb from the underside and join the margin of the LOT on the telencephalon surface in both preparations. $G, H$, Mitral cell axons on the medial side of the olfactory bulb visualized with antineuropilin-1 antibody. Mitral cell axons (arrows) projected laterally (toward the underside) in a highly orderly manner, regardless of the presence or absence of the septum. A part of the septum is seen in the bottom right corner in $G$ (asterisk). Arrowheads in $H$ indicate the cut edge from which the septum was removed. RoboN was added to cultures of septum-free preparations $(I, J)$. I, Lateral view of the telencephalon immunostained with anti-neuropilin-1 antibody as in $C$ and $D$. $J$, Medial view of the olfactory bulb immunostained with anti-neuropilin-1 antibody as in $G$ and $H$. In all of the 11 preparations examined, the projections of axons (arrows) are similar to that in the other cultures. Scale bars: $A-D, I, 1 \mathrm{~mm}$; $E, F, 500 \mu \mathrm{m} ; G, H, J, 100 \mu \mathrm{m}$.
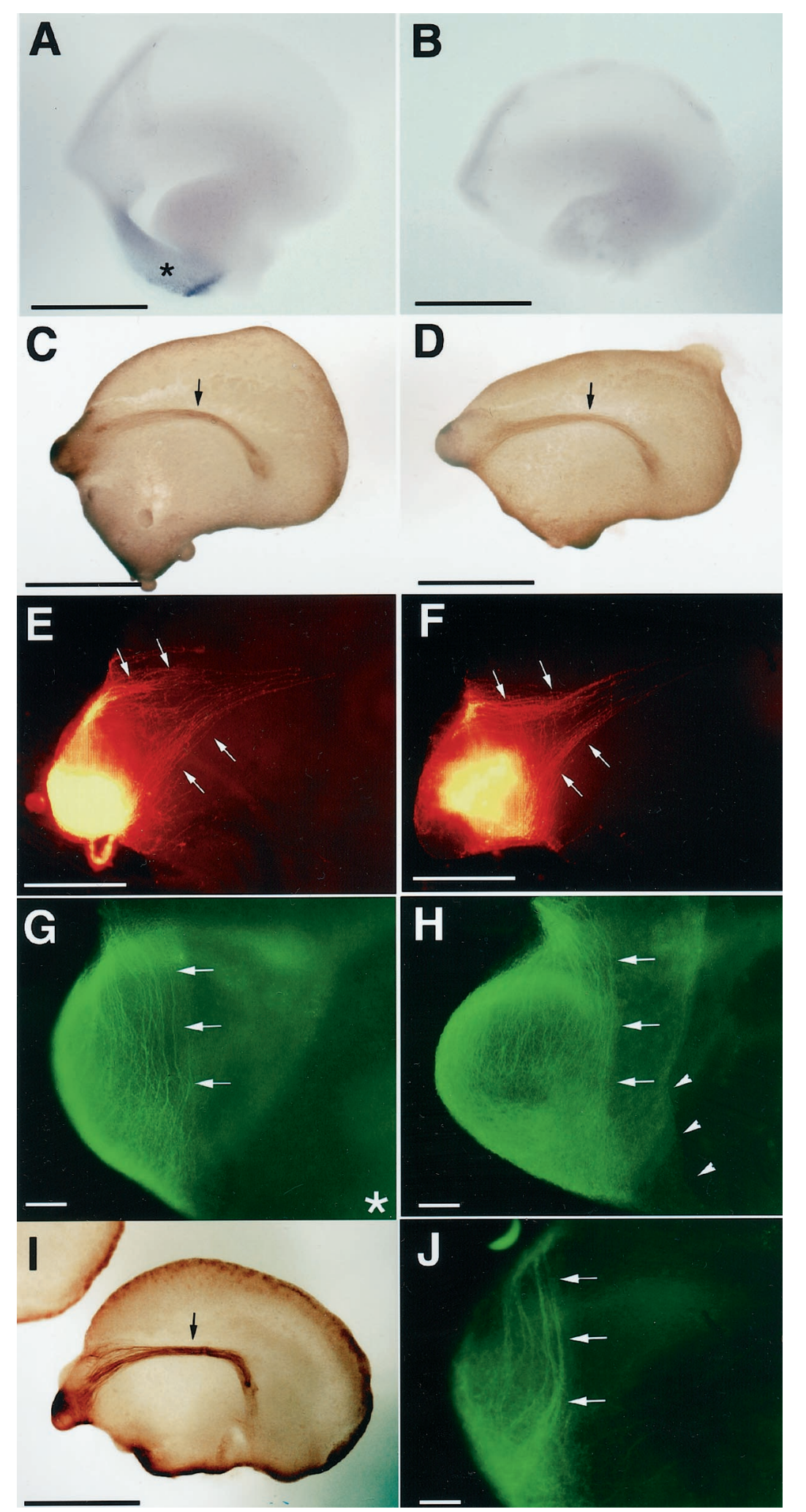

tion,such as the olfactory bulb itself, or may be an intrinsic property of mitral cells.

In the present study, we did not examine the effect of endogenous Slit or removal of the septum at a earlier stage while lot cells were still migrating toward the LOT position (Tomioka et al., 2000). Thus, there still remains a possibility that Slit or the septum controls the migration of lot cells in earlier stages of development. Also, our study cannot rule out the possible role of Slit in later stages of development, such as regulation of axonal invasion into the target area or collateral branching (Hirata and Fujisawa, 1999; Wang et al., 1999). Future studies should clarify these possibilities as well as determine the functions of Slit in other parts of the CNS (Tuyen et al., 1999; Erskine et al., 2000; Niclou et al., 2000; Ringstedt et al., 2000; Zou et al., 2000). 


\section{REFERENCES}

Brose K, Bland KS, Wang KH, Arnott D, Henzel W, Goodman CS, Tessier-Lavigne M, Kidd T (1999) Slit proteins bind Robo receptors and have an evolutionarily conserved role in repulsive axon guidance. Cell 96:795-806.

Brunjes PC, Frazier LL (1986) Maturation and plasticity in the olfactory system of vertebrates. Brain Res Rev 11:1-45.

Erskine L, Williams SE, Brose K, Kidd T, Rachel RA, Goodman CS, Tessier-Lavigne M, Mason CA (2000) Retinal ganglion cell axon guidance in the mouse optic chiasm: expression and function of Robos and Slits. J Neurosci 20:4975-4982.

Fan CM, Tessier-Lavigne M (1994) Patterning of mammalian somites by surface ectoderm and notochord: evidence for sclerotome induction by a Hedgehog homolog. Cell 79:1175-1186.

Goodman CS, Shatz CJ (1993) Developmental mechanisms that generate precise patterns of neuronal connectivity. Cell [Suppl] 72:77-98.

Hirata T, Fujisawa H (1999) Environmental control of collateral branching and target invasion of mitral cell axons during development. J Neurobiol 38:93-104.

Holmes GP, Negus K, Burridge L, Raman S, Algar E, Yamada T, Little MH (1998) Distinct but overlapping expression patterns of two vertebrate Slit homologs implies functional roles in CNS development and organogenesis. Mech Dev 79:57-72.

$\mathrm{Hu} \mathrm{H}$ (1999) Chemorepulsion of neuronal migration by Slit2 in the developing mammalian forebrain. Neuron 23:703-711.

Itoh A, Miyabayashi T, Ohno M, Sakano S (1998) Cloning and expressions of three mammalian homologues of Drosophila slit suggest possible roles for Slit in the formation and maintenance of the nervous system. Mol Brain Res 62:175-186.

Kawakami A, Kitsukawa T, Takagi S, Fujisawa H (1996) Developmentally regulated expression of a cell surface protein, neuropilin, in the mouse nervous system. J Neurobiol 29:1-17.

Kidd T, Brose K, Mitchell KJ, Fetter RD, Tessier-Lavigne M, Goodman CS, Tear G (1998) Roundabout controls axon crossing of the CNS midline and defines a novel subfamily of evolutionarily conserved guidance receptors. Cell 92:205-215.

Kidd T, Bland KS, Goodman CS (1999) Slit is the midline repellent for the Robo receptor in Drosophila. Cell 96:785-794.

Li H-S, Chen J-H, Wu W, Fagaly T, Zhou L, Yuan W, Dupuis S, Jiang ZH, Nash W, Gick C, Ornitz DM, Wu JY, Rao Y (1999) Vertebrate Slit, a secreted ligand for the transmembrane protein Roundabout, is a repellent for olfactory bulb axons. Cell 96:807-818.

Liang Y, Annan RS, Carr SA, Popp S, Mevissen M, Margolis RK, Margolis RU (1999) Mammalian homologues of the Drosophila Slit protein are ligands of the heparan sulfate proteoglycan Glypican-1 in brain. J Biol Chem 274:17885-17892.

Nakayama M, Nakajima D, Nagase T, Nomura N, Seki N, Ohara O
(1998) Identification of high-molecular-weight proteins with multiple EGF-like motifs by motif-trap screening. Genomics 51:27-34.

Niclou SP, Jia L, Raper JA (2000) Slit2 is a repellent for retinal ganglion cell axons. J Neurosci 2000:4962-4974.

Pini A (1993) Chemorepulsion of axons in the developing mammalian central nervous system. Science 261:95-98.

Ringstedt T, Braisted JE, Brose K, Kidd T, Goodman C, Tessier-Lavigne M, O'Leary DDM (2000) Slit inhibition of retinal axon growth and its role in retinal axon pathfinding and innervation patterns in the diencephalon. J Neurosci 20:4983-4991.

Sato Y, Hirata T, Ogawa M, Fujisawa H (1998) Requirement for earlygenerated neurons recognized by monoclonal antibody lot 1 in the formation of lateral olfactory tract. J Neurosci 18:7800-7810.

Schwob JE, Price JL (1984) The development of axonal connections in the central olfactory system of rats. J Comp Neurol 223:177-202.

Sugisaki N, Hirata T, Naruse I, Kawakami A, Kitsukawa T, Fujisawa H (1996) Positional cues that are strictly localized in the telencephalon induce preferential growth of mitral cell axons. J Neurobiol 29:127-137.

Tear G, Harris R, Sutaria S, Kilomanski K, Goodman CS, Seeger MA (1996) Commissureless controls growth cone guidance across the CNS midline in Drosophila and encodes a novel membrane protein. Neuron 16:501-514.

Tessier-Lavigne M, Goodman CS (1996) The molecular biology of axon guidance. Science 274:1123-1131.

Tomioka N, Osumi N, Sato Y, Inoue T, Nakamura S, Fujisawa H, Hirata $\mathrm{T}$ (2000) Neocortical origin and tangential migration of guidepost neurons in the lateral olfactory tract. J Neurosci 20:5802-5812.

Tuyen K, Ba-Charvet N, Brose K, Marillat V, Kidd T, Goodman CS, Tessier-Lavigne M, Sotelo C, Chédotal A (1999) Slit2-mediated chemorepulsion and collapse of developing forebrain axons. Neuron 22:463-473.

Wang KH, Brose K, Arnott D, Kidd T, Goodman CS, Henzel W, Tessier-Lavigne M (1999) Biochemical purification of a mammalian Slit protein as a positive regulator of sensory axon elongation and branching. Cell 96:771-784.

Wu W, Wong K, Chen J-H, Jiang Z-H, Dupuis S, Wu JY, Rao Y (1999) Directional guidance of neuronal migration in the olfactory system by the protein Slit. Nature 400:331-336.

Yuan W, Zhou L, Chen J-H, Wu JY, Rao Y, Ornitz DM (1999) The mouse Slit family: secreted ligands for Robo expressed in patterns that suggest a role in morphogenesis and axon guidance. Dev Biol 212:290306.

Zhu Y, Li H-S, Zhou L, Wu JY, Rao Y (1999) Cellular and molecular guidance of GABAergic neuronal migration from an extracortical origin to the neocortex. Neuron 23:473-485.

Zou Y, Stoeckli E, Chen H, Tessier-Lavigne M (2000) Squeezing axons out of the gray matter: a role for Slit and Semaphorin proteins from midline and ventral spinal cord. Cell 102:363-375. 